\title{
Isolation and Characterisation of 2-Tert-butyl-8-hydroxyquinoline as a Crystalline Solid and Its Blue Fluorescent Li Complex
}

\author{
Poopathy Kathirgamanathan, ${ }^{1}$ Sivagnanasundram Surendrakumar, \\ Seenivasagam Ravichandran, ${ }^{1}$ and Alexander J. Blake ${ }^{2}$ \\ ${ }^{1}$ Organic Electronics, School of Engineering, Brunel University, Uxbridge UB8 3PH, UK \\ ${ }^{2}$ School of Chemistry, University of Nottingham, Nottingham NG7 2RD, UK
}

Correspondence should be addressed to Poopathy Kathirgamanathan; p.kathirgamanathan@brunel.ac.uk and Alexander J. Blake; a.j.blake@nottingham.ac.uk

Received 12 June 2013; Revised 26 November 2013; Accepted 1 December 2013; Published 4 February 2014

Academic Editor: Steven Suib

Copyright (c) 2014 Poopathy Kathirgamanathan et al. This is an open access article distributed under the Creative Commons Attribution License, which permits unrestricted use, distribution, and reproduction in any medium, provided the original work is properly cited.

2-Tert-butyl-8-hydroxyquinoline (2-TB-8-hq) has been isolated as a crystalline solid and its X-ray structure elucidated, resolving three decades of controversy, since it was previously wrongly reported as yellow oil by some other workers. An improved synthetic method has been developed which increases the yield from $20 \%$ to $60 \%$. The lithium complex of 2-TB-8-hq is blue emitting and the HOMO and LUMO levels are lowered by $0.86 \mathrm{eV}$ and $0.74 \mathrm{eV}$, respectively, compared with the parent lithium 8-hydroxyquinolinolate (Li 8-hq).

\section{Introduction}

8-Hydroxyquinoline (8-hq) and its derivatives have been the subject of intense study over the last thirty years because of their use in analytical chemistry, but more recently the focus of interest in this class of compounds has been expanded due to the use of metal complexes of 8-hq in high-efficiency multilayer organic light-emitting devices (OLEDs) [1]

Metal complexes of 8-hq, aluminium quinolinolate $\left(\mathrm{Alq}_{3}\right)$, and zirconium quinolinolate $\left(\mathrm{Zrq}_{4}\right)$ have been extensively studied owing to their high stability and their application in commercial OLEDs [2-4]. Metal complexes of sterically hindered 2-substituted 8-hq have also attracted great interest [4-8] because of the possibility of colour tuning as well as ability to manipulate the HOMO-LUMO levels by forming mixed ligand complexes [7]. Aluminium does not form the usual tris complex with 2-substituted 8 -hq due to steric effects and the small size of the $\mathrm{Al}^{3+}$ cation, but it rather forms heteroleptic complexes of the type $\mathrm{ML}_{2} \mathrm{~L}^{\prime}$. For example, [bis(2-methyl-8-quinolato)(4phenylphenolato) $\mathrm{Al}(\mathrm{III})]$ (also known as $\mathrm{BAlq}_{2}$ ) emits blue light, whereas the parent $\mathrm{Alq}_{3}$ emits yellow-green light. Early interest in $\mathrm{BAlq}_{2}$ was based on it being a very good host for blue-light-emitting dopants (e.g., perylene), but it is now employed as a host as well as a hole blocker in red phosphorescent OLEDs [8].

We have been interested in OLEDs for nearly 20 years and in 8 -hq derivatives as a means of manipulating the photoluminescence and the electronic properties of metal complexes. As such, we were interested in synthesising $\mathrm{Li}(\mathrm{I}), \mathrm{Zn}(\mathrm{II}), \mathrm{Al}(\mathrm{III})$, and $\mathrm{Zr}(\mathrm{IV})$ complexes of 2-tert-butyl8-hydroxyquinoline (2-TB-8-hq). The synthesis of 2-TB-8-hq was first reported by Kazi in 1971 to afford a white crystalline solid (m.p. $72-73^{\circ} \mathrm{C}$ ) in $20 \%$ yield [9]. In 1979, Kazi's report was disputed by Thompson and Stubley [10] who claimed to have isolated 2-TB-8-hq as a yellow liquid in 3.4\% yield by direct reaction of tert-butyllithium with 8 -hq and in $15 \%$ yield when a protective methylation-demethylation route was employed. In 2001, Delapierre et al. [11] concurred with Thompson and Stubley that 2-TB-8-hq was a yellow liquid, while achieving a higher yield of $42 \%$. 

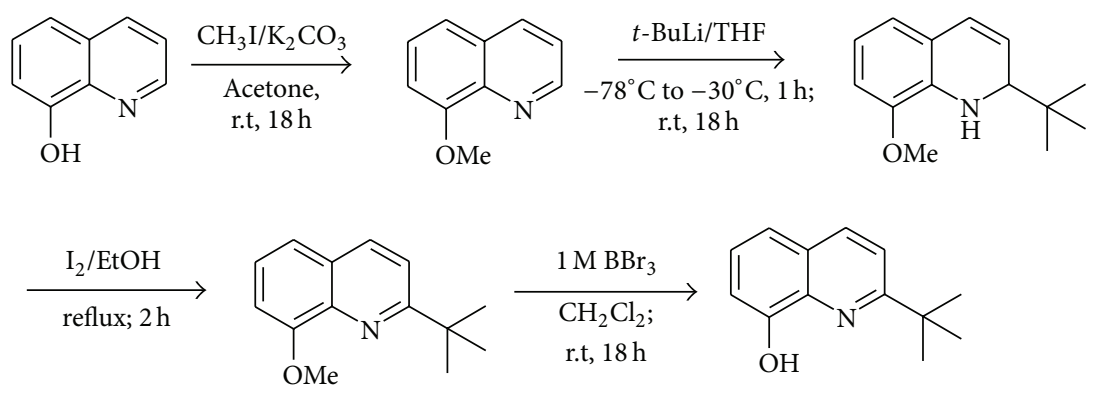

SCHEME 1<smiles>Oc1cccc2cccnc12</smiles>

8-hq

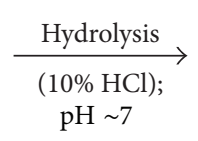

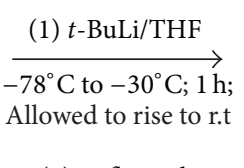

(2) Reflux, $1 \mathrm{~h}$<smiles>CC(C)(C)c1ccc2cccc(O)c2n1</smiles><smiles>COc1cccc2c1NC(C(C)(C)C)C=C2</smiles>

Yellowish suspension

[A]<smiles>CC(C)(C)c1ccc2cccc3c2[n+]1[AlH]O3</smiles>

Orange solution

[B]

(Yield 61\%)

2-TB-8-hq

SCHEME 2

This paper reports not only a simple, improved synthesis of 2-TB-8-hq as a crystalline solid (m.p. $73^{\circ} \mathrm{C}$ ) in over $60 \%$ yield but also its crystal structure, resolving three decades of controversy and confirming that Kazi's report [9] was indeed correct.

\section{Results and Discussion}

Firstly, the preparation of 2-tert-butyl-8-hydroxyquinoline was attempted by protecting the 8-hydroxy group by methylation using methyl iodide and potassium carbonate, followed by treatment with tert-butyllithium at $-78^{\circ} \mathrm{C}$. The temperature was kept below $-30^{\circ} \mathrm{C}$ for $1 \mathrm{~h}$ before allowing it to rise to room temperature. After the usual work-up of the reaction mixture which contains the dihydroquinoline, it was oxidised by refluxing with iodine in ethanol for $2 \mathrm{~h}$. Finally, the demethylation was carried out using boron tribromide in dichloromethane at room temperature to give the required 2 TB-8-hq in 66\% yield. See Scheme 1.

The procedure was later modified without the protection of the methyl group but by the addition of excess tertbutyllithium at $-78^{\circ} \mathrm{C}$ as before. The lithium salt was carefully oxidized by bubbling air through the reaction mixture for 1 hour, during which the yellow suspension became an orange solution. Finally, the lithium derivative was hydrolysed by the addition of dilute hydrochloric acid to give the target compound 2-TB-8-hq in a comparatively moderate yield of $61 \%$. See Scheme 2.
Since the latter method (Reaction Scheme 2) was found to be easier to carry out (experimental work-up) using less expensive chemicals, this alternative synthesis was utilised to scale the product up to $50 \mathrm{~g}$ and purified by column chromatography (ethyl acetate-petroleum ether $\left(40-60^{\circ} \mathrm{C}\right)$ [19:1]) in pure form (99\%) as confirmed by gas chromatography and ${ }^{1} \mathrm{H}$ NMR spectroscopy. The colourless thick liquid obtained was triturated with petroleum ether $\left(40-60^{\circ} \mathrm{C}\right)$ and a few millilitres of ethyl acetate. Cooling the saturated solution in an ice bath gave a colourless crystalline solid form of 2-TB-8-hq (MP 73 C (DSC, onset)). Single crystal Xray crystallography further confirmed its identity. The crystal structure of 2-TB-8-hq was found to be orthorhombic. The ORTEP diagram is shown in Figure 1.

We attribute the poor yield obtained by Kazi [9] to the fact that he did not fully oxidise the dihydroquinoline intermediate $[\mathrm{A}]$ : he did not bubble air or oxygen through the reaction mixture; neither did he add other oxidants. However, his observation that 2-TB-8-hq was solid with m.p. of $72^{\circ} \mathrm{C}$ is correct, and the authenticity of his compound was supported by elemental analysis results and NMR spectroscopy. We believe that the reason why Thompson and Stubley [10] and Delapierre et al. [11] obtained a yellowish liquid rather than a solid is due to the presence of impurities such as the intermediate $[\mathrm{A}]$ and the lithium complex [B] (see Reaction Scheme 2).

We synthesised the lithium complex of 2-TB-8-hq in accordance with our previously published method [12]. 
TABle 1: Melting points, HOMO-LUMO values, band gaps, and photoluminescence of Li-8-hq, Li-2-Me-8-hq, and Li-2-TB-8-hq.

\begin{tabular}{|c|c|c|c|c|c|}
\hline Compound & Melting point $/{ }^{\circ} \mathrm{C}^{\mathrm{a}}$ & $\mathrm{HOMO} / \mathrm{eV}^{\mathrm{b}}$ & 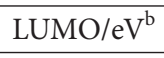 & $E_{g} / \mathrm{ev}^{\mathrm{c}}$ & Emission maximum/nm \\
\hline Li-8-hq ${ }^{\mathrm{s}}$ & 362 & -5.00 & -2.08 & $2.92 \pm 0.04$ & $491 \pm 2$ \\
\hline $\mathrm{Li}-2-\mathrm{Me}-8-\mathrm{hq}^{\mathrm{s}}$ & 397 & -5.60 & -2.60 & $3.00 \pm 0.03$ & $485 \pm 2$ \\
\hline $\mathrm{Li}-2-\mathrm{TB}-8-\mathrm{hq}^{\mathrm{s}}$ & $>400$ & -5.86 & -2.82 & $3.04 \pm 0.02$ & $475 \pm 2$ \\
\hline
\end{tabular}

${ }^{\mathrm{a}}$ From DSC. ${ }^{\mathrm{b}}$ Obtained from cyclic voltammetry in $1 \mathrm{mM}$ analyte, supporting electrolyte $0.1 \mathrm{M}$ tetrabutylammonium tetrafluoroborate in dichloromethane. Pt working and $\mathrm{Pt}$ auxiliary electrodes and $\mathrm{Ag} / \mathrm{AgCl}$ (reference electrode). ${ }^{\mathrm{c}}$ Determined from the absorption edge of vacuum thermal evaporated thin films. ${ }^{\mathrm{s}}$ Purified by vacuum sublimation.

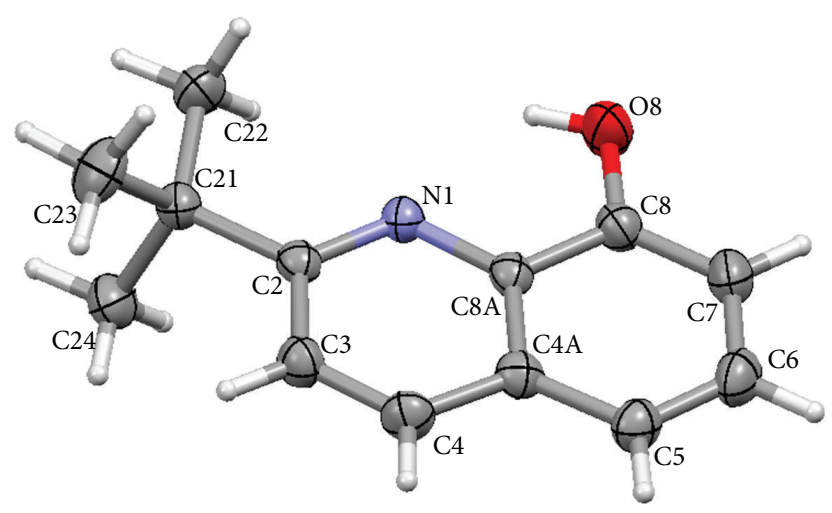

FIGURE 1: ORTEP diagram with atomic numbering scheme of 2-TB8-hq. Ellipsoids are drawn at the $30 \%$ probability level.

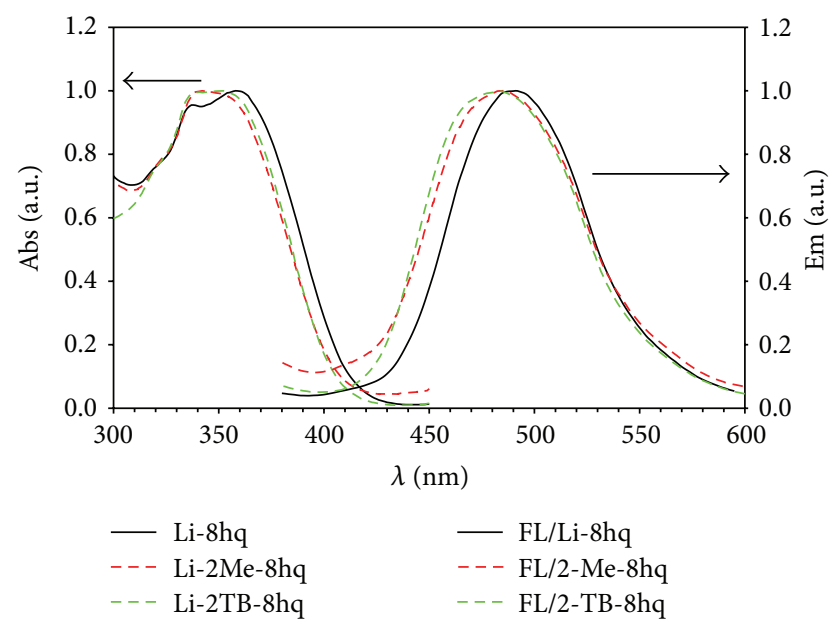

FIGURE 2: Absorption and fluorescence spectra of Li-8-hq, Li-2Me8hq and Li-2TB-8hq.

These complexes are used in OLEDs as efficient electron injectors which evaporate at much lower temperature $\left(280^{\circ} \mathrm{C}\right)$ than $\mathrm{LiF}$ which requires $550^{\circ} \mathrm{C}$ under vacuum thermal evaporation conditions. The vacuum thermal evaporated thin films of complex (Li 2-TB-8-hq), lithium 2methyl-8-hydroxyquinolinolate (Li 2Me-8-hq), and lithium 8-hydroxyquinolinolate ( $\mathrm{Li} 8$-hq) have emission maxima at 475,485 , and $491 \mathrm{~nm}$, respectively (Figure 2): full details will be published elsewhere. The blue shift in the emission wavelength upon 2-substitution is consistent with the presence of steric effects [5].
The electronic and thermal properties are summarised in Table 1.

The remarkable shift in the HOMO-LUMO values of 2-substituted 8-hq complexes shows that the electronic properties can easily be tuned by simple substitution at the 2-position of 8-hq. Similarly, preliminary experiments show that a methanolic solution of the bis complex $\mathrm{Al}(2-\mathrm{TB}-8-\mathrm{hq})_{2}\left(\mathrm{o}-{ }^{\mathrm{i}} \mathrm{Pr}\right)$ has an emission maximum at $442 \mathrm{~nm}$ in contrast to $\mathrm{BAlq}_{2}$ and $\mathrm{Alq}_{3}$ which exhibit emission maxima at 490 and $509 \mathrm{~nm}$, respectively. Further synthetic work is ongoing with the aim of preparing the $\mathrm{BAlq}_{2}$ analogue of 2-TB-8-hq.

\section{Experimental Section}

3.1. Synthesis of 2-Tert-butyl-8-hydroxyquinoline. 8-Hydroxyquinoline (25 g; 0.17 mole) in dry THF $(100 \mathrm{~mL})$ was cooled to $-78^{\circ} \mathrm{C}$. To the magnetically stirred solution, tert-butyllithium was slowly siphoned (1.7 M in hexane, $253 \mathrm{~mL}, 0.43$ mole) under nitrogen atmosphere. The solution was kept below $-30^{\circ} \mathrm{C}$ for $1 \mathrm{~h}$ and then allowed to rise to room temperature. The solution was then stirred and refluxed for $1 \mathrm{~h}$ and then cooled to room temperature. Air was bubbled through the mixture for 90 minutes, during which the light yellow solid in the solution disappeared and the solution became light red brown in colour. The reaction mixture was neutralised by the addition of dilute $\mathrm{HCl}(10 \%)$ and the product was extracted with dichloromethane $(3 \times 100 \mathrm{~mL})$. The combined organic phase was washed with brine and water and then dried over anhydrous magnesium sulphate. The solvent was evaporated under reduced pressure to give a light brown liquid.

The residue was purified by column chromatography over silica gel using ethyl acetate-petroleum ether $\left(40-60^{\circ} \mathrm{C}\right)$ [19:1] to give colourless liquid. Trituration with petroleum ether with a few drops of ethyl acetate gave a colourless crystalline solid ( $21 \mathrm{~g}, 61 \%)$. M.p $73^{\circ} \mathrm{C}$ (DSC, onset). Elemental analysis found: $\mathrm{C}, 77.86 ; \mathrm{H}, 7.67 ; \mathrm{N}, 7.13 . \mathrm{C}_{13} \mathrm{H}_{15} \mathrm{NO}$ requires C, $77.58 \mathrm{H}, 7.51$, and N, 6.96\%. ${ }^{1} \mathrm{H}$ NMR $\left(500 \mathrm{MHz}, \mathrm{CDCl}_{3}\right.$ )

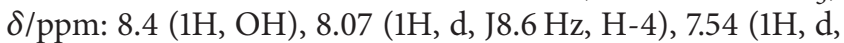
J8.6 Hz, H-3), 7.38 (1H, t, J7.6 Hz, H-6), 7.28 (1H, dd, J1.1 and J8.2 Hz, H-5), 7.15 (1H, dd, J1.2 and J7.6 Hz, H-7), and 1.45 $\left(9 \mathrm{H}, \mathrm{s},-\left(\mathrm{CH}_{3}\right)_{3}\right)$. Mass spectrum: $\mathrm{M}^{+} 201(37 \%) ; 186, \mathrm{M}-\mathrm{CH}_{3}$ (100); 159, M-C $\left(\mathrm{CH}_{3}\right)_{2} ; 145, \mathrm{M}-\mathrm{C}\left(\mathrm{CH}_{3}\right)_{3}+\mathrm{H}$, and 117, M$\mathrm{CO}-\mathrm{C}\left(\mathrm{CH}_{3}\right)_{3}(10)$.

3.2. Preparation of 8-Methoxyquinoline. To a mixture of 8 hydroxyquinoline $(10.0 \mathrm{~g} ; 0.069$ mole) and anhydrous potassium carbonate ( $48 \mathrm{~g}$; 0.35 mole) in acetone $(100 \mathrm{~mL})$, methyl 
iodide ( $5.2 \mathrm{~mL} ; 0.083$ mole) was added and stirred at room temperature for $18 \mathrm{~h}$. The reaction was filtered and washed with acetone and the filtrate was evaporated. The residue was dissolved in dichloromethane $(150 \mathrm{~mL})$ and was washed with water. The organic phase was dried over anhydrous magnesium sulphate and solvent was removed to give a red-brown oil. The product was purified by column chromatography over silica gel dichloromethane-methanol $[98: 2]$ to give a low melting solid (10.2 g, 91\%). Elemental analysis found: C, 74.87; $\mathrm{H}, 5.94 ; \mathrm{N}, 8.59 . \mathrm{C}_{10} \mathrm{H}_{9} \mathrm{NO}$ requires $\mathrm{C}, 75.45 ; \mathrm{H}, 5.70$ and $\mathrm{N}$, $8.79 \%$.

3.3. Preparation of 2-Tert-butyl-8-methoxyquinoline. 8-Methoxyquinoline ( $10 \mathrm{~g} ; 0.063$ mole) was dissolved in dry tetrahydrofuran $(50 \mathrm{~mL})$ and was cooled to $-78^{\circ} \mathrm{C}$. tertButyllithium (1.7 M; $45 \mathrm{~mL} ; 0.076$ mole) was added slowly and the reaction mixture was kept below $-30^{\circ} \mathrm{C}$ for $1 \mathrm{~h}$ and was allowed to rise to room temperature. After stirring at room temperature for $18 \mathrm{~h}$, the reaction mixture was poured into ice water and was extracted with dichloromethane (2 $\times 150 \mathrm{~mL}$ ). The organic phase was washed with brine and water and was dried over anhydrous magnesium sulphate and solvent was removed to give a yellow orange liquid, $12 \mathrm{~g}$. The TLC examination showed the absence of starting material.

The product was dissolved in ethanol $(70 \mathrm{~mL})$ and refluxed with iodine (18 g; 0.07 mole) for $2 \mathrm{~h}$; solvent was removed and then was extracted with dichloromethane and $10 \%$ sodium thiosulphate. The organic phase after usual workup was purified by column chromatography over silica gel ethyl acetate-petroleum ether $\left(40-60^{\circ} \mathrm{C}\right)$ [1:9] to give 2tert-butyl-8-methoxyquinoline as a yellow oil $(9.8 \mathrm{~g}, 77 \%)$. Elemental analysis found: $\mathrm{C}, 77.91 ; \mathrm{H}, 8.12 ; \mathrm{N}, 6.42 . \mathrm{C}_{14} \mathrm{H}_{17} \mathrm{NO}$ requires $\mathrm{C}, 78.10 ; \mathrm{H}, 7.96$ and $\mathrm{N}, 6.50 \%$.

3.4. Preparation of 2-Tert-butyl-8-hydroxyquinoline. 2-Tertbutyl-8-methoxyquinoline ( $9.8 \mathrm{~g} ; 0.045 \mathrm{~mole})$ was dissolved in dichloromethane $(60 \mathrm{~mL})$ and to the magnetically stirred solution at room temperature was added $1 \mathrm{M}$ boron tribromide solution in dichloromethane $(55 \mathrm{~mL} ; 0.055$ mole) under nitrogen atmosphere. The reaction mixture was stirred at room temperature for $18 \mathrm{~h}$, cooled in ice-water bath, carefully quenched with cold water, and finally extracted with dichloromethane. The organic phase was dried over anhydrous magnesium sulphate and solvent was removed to give a greenish liquid. This was purified by column chromatography over silica gel ethyl acetate-petroleum ether $\left(40-60^{\circ} \mathrm{C}\right)[1: 9]$ to give a light yellow liquid which on cooling gave a colourless solid $(6.0 \mathrm{~g}, 66 \%)$. M.p $73^{\circ} \mathrm{C}$, DSC (onset). Elemental analysis found: $\mathrm{C}, 77.39 ; \mathrm{H}, 7.51 ; \mathrm{N}, 6.83 . \mathrm{C}_{13} \mathrm{H}_{15} \mathrm{NO}$ requires $\mathrm{C}, 77.58$; $\mathrm{H}, 7.51$ and $\mathrm{N}, 6.96 \%$.

Crystal Data for 2-TB-8-hq. $\mathrm{C}_{13} \mathrm{H}_{15} \mathrm{NO}, \quad M=201.26$, orthorhombic, $a=12.5619(6), b=11.1072(7), c=16.0684(7) \AA$, $U=2242.0(2) \AA^{3}, T=295(2) \mathrm{K}$, space group $P b c a, Z=8$, 4106 reflections measured, 2175 unique $\left(R_{\text {int }}=0.041\right)$. Final $R_{1}[F>4 \sigma(F)]=0.0597, w R_{2}\left(F^{2}\right)=0.157$ (all data).

\section{Conclusions}

In conclusion, we have proven that $2-\mathrm{TB}-8 \mathrm{hq}$ is indeed a solid (m.p. $73^{\circ} \mathrm{C}$ ) and can easily be synthesised in high yield. It is not a liquid as some authors have previously reported $[10,11]$, solving the three decades of controversy. We have also made the same ligand by an alternative methylation route and obtained crystalline solid with $66 \%$ yield. The lithium complex of 2-TB-8-hq is blue-emitting and the HOMO and LUMO levels are lowered by $0.86 \mathrm{eV}$ and $0.74 \mathrm{eV}$, respectively, compared with the parent Li 8-hq.

\section{Conflict of Interests}

The authors declare that there is no conflict of interests regarding the publication of this paper.

\section{Acknowledgments}

The authors thank Dr. Vincent Arkley for stimulating discussions and for his comments on earlier synthetic methods for 2-TB-8-hq. They thank Miss V. Surendrakumar for obtaining a copy of the Ph.D. thesis of G. M. Kazi at the Imperial College, UK. They also thank Professors M. Sarhadi, G. Rodgers, and J. Silver and Dr. D. R. Rosseinsky for encouragement. They thank EPSRC for the award of a diffractometer.

\section{References}

[1] P. Kathirgamanathan, S. Surendrakumar, J. Antipan-Lara et al., "Novel lithium Schiff-base cluster complexes as electron injectors: synthesis, crystal structure, thin film characterisation and their performance in OLEDs," Journal of Materials Chemistry, vol. 22, no. 13, pp. 6104-6116, 2012.

[2] C. W. Tang and S. A. Vanslyke, "Organic electroluminescent diodes," Applied Physics Letters, vol. 51, no. 12, pp. 913-915, 1987.

[3] M. Rajeswaran, W. J. Begley, L. P. Olson, and S. Huo, "Steric effects of substituted quinolines on lithium coordination geometry," Polyhedron, vol. 26, no. 14, pp. 3653-3660, 2007.

[4] P. Kathirgamanathan, S. Surendrakumar, J. Antipan-Lara et al., "Discovery of two new phases of zirconium tetrakis(8hydroxyquinolinolate): synthesis, crystal structure and their electron transporting characteristics in organic light emitting diodes (OLEDs)," Journal of Materials Chemistry, vol. 21, no. 6, pp. 1762-1771, 2011.

[5] J. C. Deaton, D. W. Place, C. T. Brown, M. Rajeswaran, and M. E. Kondakova, "The blue aluminum and gallium chelates for OLEDs," Inorganica Chimica Acta, vol. 361, no. 4, pp. 1020-1035, 2008.

[6] R. Meerheim, B. Lüssem, and K. Leo, "Efficiency and stability of $\mathrm{p}$-i-n type organic light emitting diodes for display and lighting applications," Proceedings of the IEEE, vol. 97, no. 9, pp. 1606$1626,2009$.

[7] P. Kathirgamanathan, A. K. Lay, G. Subramaniam, G. Paramaswara, and S. Selvaranjan, WO, 2006/024831 A1.

[8] T. Tsuji, S. Kawami, S. Miyasuchi et al., in Proceedings of the International Symposium Digest of Technical Papers (SID '04), vol. 35, p. 900, 2004.

[9] G. M. Kazi, [Ph.D. thesis], University of London, 1971. 
[10] M. Thompson and E. A. Stubley, "Synthesis of the analytical ligand 2-tert.-butyl-8-hydroxyquinoline," Talanta, vol. 26, no. 7, pp. 601-602, 1979.

[11] G. Delapierre, J. M. Brunel, T. Constantieux, and G. Buono, "Design of a new class of chiral quinoline-phosphine ligands. Synthesis and application in asymmetric catalysis," Tetrahedron Asymmetry, vol. 12, no. 9, pp. 1345-1352, 2001.

[12] P. Kathirgamanathan, PCT WO, 2000/32717. 

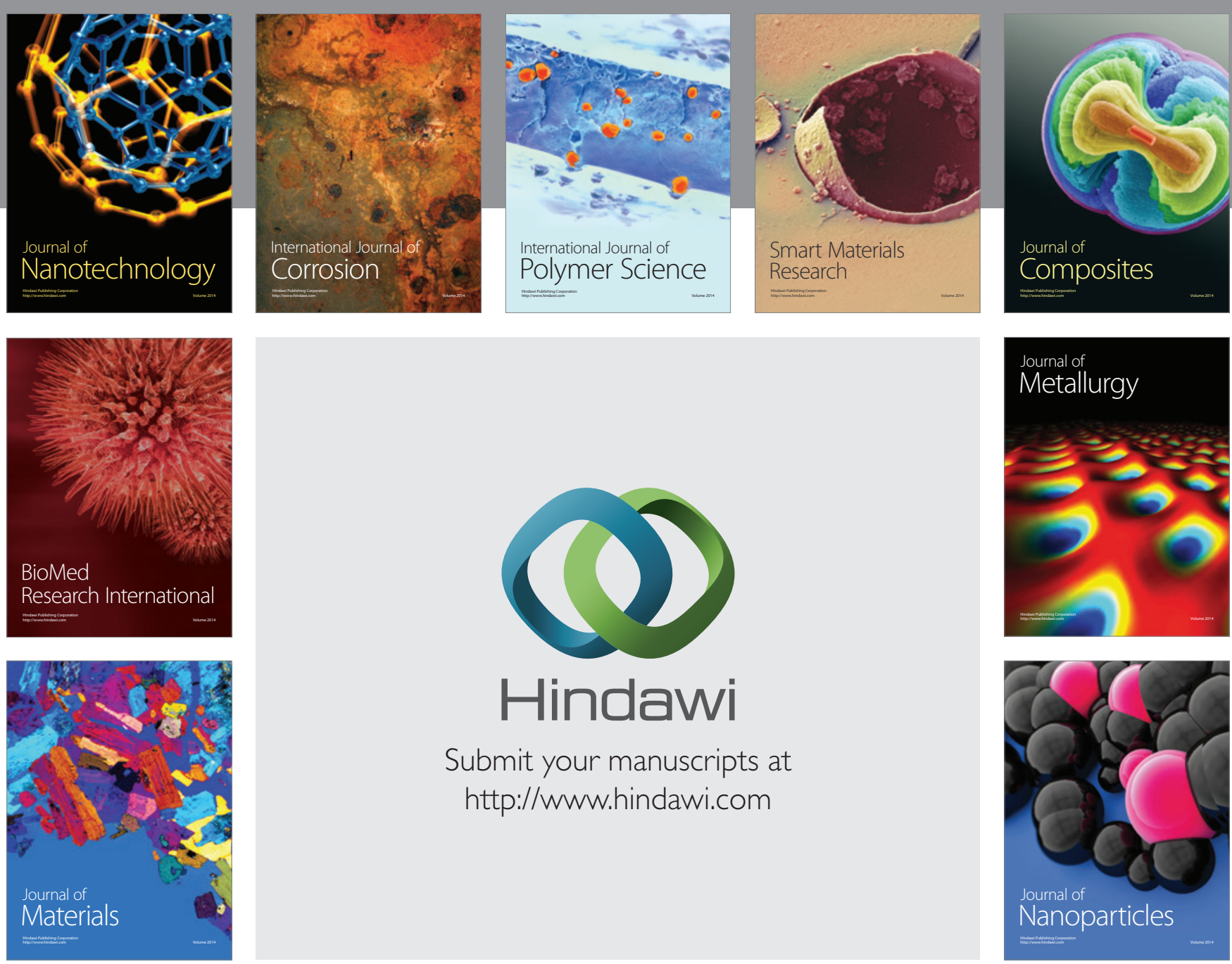

Submit your manuscripts at http://www.hindawi.com
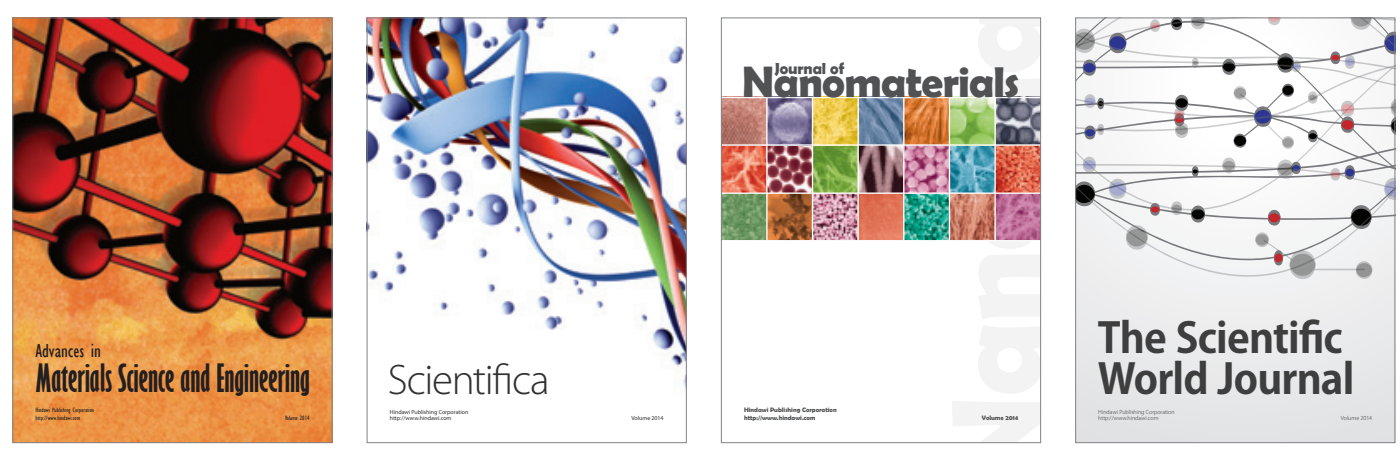

\section{The Scientific World Journal}
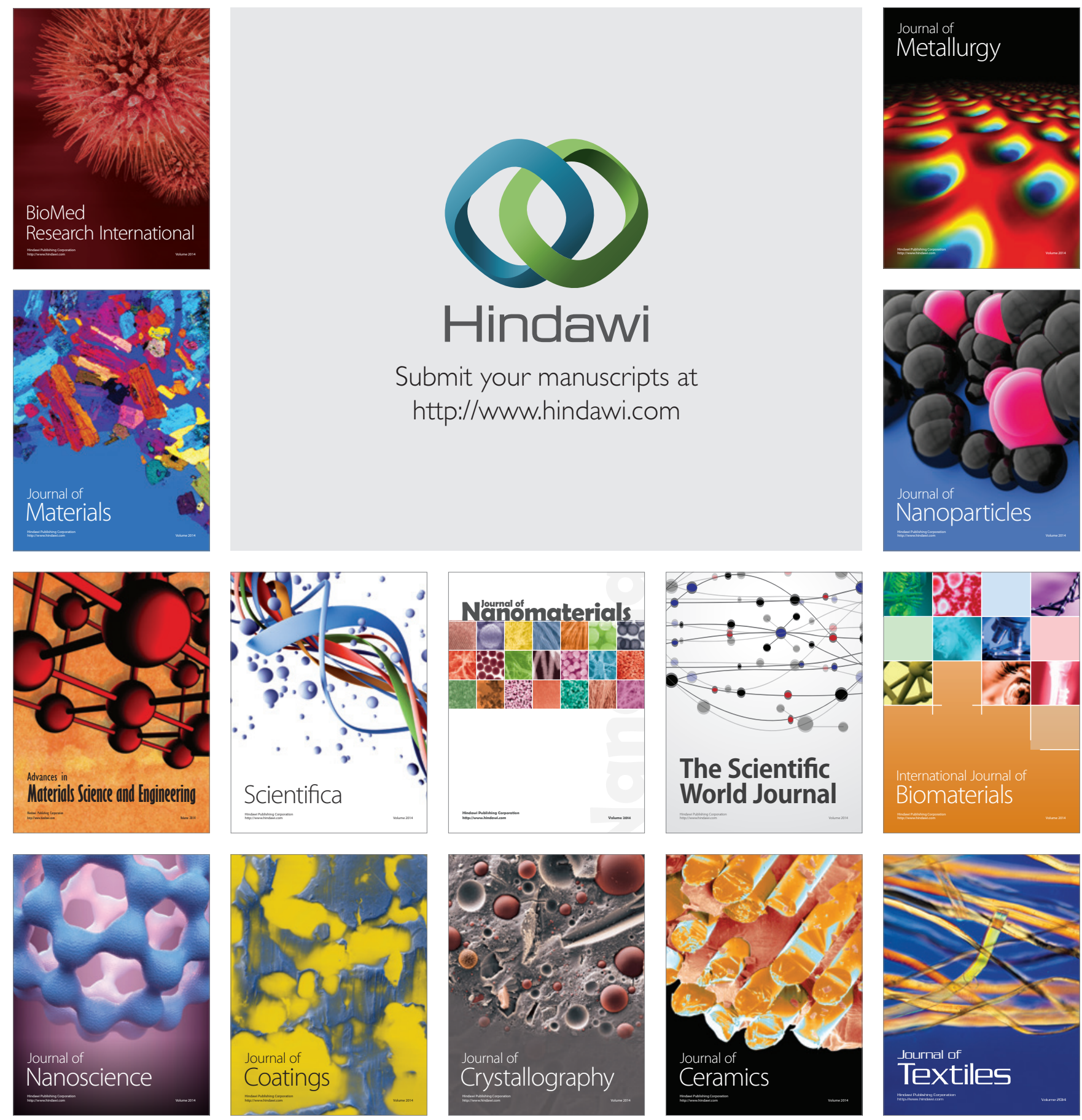